\title{
Dor crônica em idosos e sua influência nas atividades da vida diária e convivência social
}

\author{
Chronic pain in elderly and itsinfluenœe in daily adivities and social living
}

Resumo

Kátia Lilian Sedrez Celich*

Cátia Galon*

Estudo transversal que objetivou caracterizar a dor crônica em idosos residentes na cidade de Cruzaltense/RS, a fim de evidenciar a influência desta na vida diária e na convivência social. A amostra abrangeu 48 idosos. A coleta de dados ocorreu através da aplicação de um questionário com questões fechadas. Os dados foram analisados através da estatística descritiva. Dos 48 pesquisados, 56,25\% referiram dor crônica: 16 do sexo feminino e 11, do masculino. Os idosos apresentavam idade entre 60 e 83 anos, com média de 71,5 , sendo que $81,5 \%$ apresentam alguma patologia com diagnóstico médico. Predominam os idosos casados (55,5\%), embora seja significativo o percentual de viúvos (40,7\%). Quanto à ocupação pregressa, 92,6\% eram agricultores. Os lugares mais prevalentes de dor crônica foram: coluna lombar e cervical, pernas, articulação do joelho e membros superiores. A intensidade da dor, segundo a escala numérica visual (VAS), variou de 1 a 10. Em relação ao tipo de dor, destacaram: sensação de dolorimento, queimação, latejante, lacerante e aguda podendo ocorrer diariamente, eventualmente e associada a esforços. A dor está entre os principais fatores que limitam a possibilidade do idoso em manter seu cotidiano de maneira normal, impactando negativamente sua qualidade de vida, prejudicando, de algum modo a realização das atividades de vida diária, bem como restringindo a convivência social, o que pode conduzir ao isolamento.

\footnotetext{
Universidade Regional Integrada do Alto Uruguai e das Missões

Curso de Graduação em Enfermagem. Erechim, RS, Brasil
}

Correspondência / Correspondence

Kátia Lilian Sedrez Celich

E-mail: celich@clicalpha.com.br

Texto elaborado a partir da pesquisa cujo resultado culminou no Trabalho de Conclusão do Curso de Enfermagem da Universidade Regional Integrada do Alto Uruguai e das Missões - Campus de Erechim - RS. Junho de 2008.

\author{
Palavras-chave: \\ Idoso. Medição da \\ Dor. Enfermagem. \\ Estudos Transver- \\ sais. Qualidade de \\ Vida.
}


Abstract

This is a cross-sectional study which aimed to characterize chronic pain in elderly residents in the town of Cruzaltense/RS, in order to show its influence in their daily life and in social life. The sample comprised 48 old elderly people. Data collection was done through the application of a questionnaire with closed questions. Data were analyzed using descriptive statistics. From the total sample, $56.25 \%$ referred chronic pain, being 16 females and 11 males, whose ages ranged from 60 to 83 , average of $71.5 ; 81,5 \%$ presented some pathology with medical diagnosis. There was a predominance of married elderly (55.5\%), although the percentage of widows is $40.7 \%$. Regarding the occupation of these people, $92.6 \%$ were agriculturists. The places with most prevalent pain were: lumbar and cervical spine, legs, knee joints and superior members. The intensity of pain, according to the Visual Numeric Scale (VNS), varied from 1 to 10 . Regarding the type of pain, they highlighted: feeling of pain, burning, throbbing, lacerating and intense. These events can occur daily, eventually or associated with any sort of effort. Pain is among the main factors that limit the possibility of the elderly to keep their everyday normally, with a negative impact on the elderly's quality of life, somehow damaging the accomplishment of daily activities, as well as restraining social life, even leading to isolation.
Key words: Aged. Pain

Measurement.

Nursing. Cross-

Sectional Studies.

Quality of Life.

\section{INTRODUÇÃOO}

A transição demográfica é um fenômeno de amplitude mundial, assim, a longevidade é um fato que está também presente na sociedade brasileira. No entanto, essa transformação vem acompanhada do aumento na incidência de doenças incapacitantes, crônicas e degenerativas, que contribuem significativamente para o aparecimento de queixas de dor.

A dor, quando presente na vida do idoso, instiga, consome, enfraquece o que ele tem de mais precioso - a vida. A dor confronta o idoso com sua fragilidade e ameaça sua segurança, autonomia e independência, impedindo muitas vezes sua capacidade de realizar as atividades da vida diária, bem como limitando sua capacidade de interação e convívio social - situações que diminuem consideravelmente sua qualidade de vida.

A dor é considerada pela Associação Internacional de Estudos da Dor (IASP) como uma experiência desagradável, sensitiva e emocional, associada ou não ao dano real ou potencial de lesões dos tecidos e relacionada com a memória individual, com as expectativas e as emoções de cada pessoa, podendo ser aguda ou crônica. ${ }^{1}$ Trata-se de uma manifestação subjetiva, que envolve mecanismos físicos, psíquicos e culturais. ${ }^{2}$

A dor aguda surge de forma súbita e tem como função alertar o indivíduo para o perigo de uma lesão. A dor crônica é consi- 
derada aquela com duração maior de seis meses, ou que ultrapassa o período usual de recuperação esperado para a causa desencadeante da dor. ${ }^{3}$ A dor crônica merece maior atenção por parte dos profissionais de saúde, pois influencia negativamente no cotidiano do indivíduo.

A dor em idosos é um sério problema de saúde pública, que necessita ser diagnosticado, mensurado, avaliado e devidamente tratado pelos profissionais de saúde, uma vez que são esses os agentes capazes de, através de intervenções, minimizar a morbidade e melhorar a qualidade de vida desses indivíduos. ${ }^{4}$ Envelhecer não é um obstáculo à vida, mas sim, o envelhecimento sem saúde e sem qualidade de vida. ${ }^{5} \mathrm{Ou}$ seja, muitas queixas do idoso relacionadas à dor são atribuídas à idade e consideradas próprias ao processo de envelhecimento; deixam, assim, de ser tratadas, o que influencia negativamente a qualidade de vida na velhice. Diante destas considerações, observa-se a necessidade de se ter um olhar mais crítico e reflexivo em relação a essa problemática. Os profissionais de enfermagem, que de um modo geral convivem mais próximos dos idosos na comunidade, devem desenvolver sensibilidade para prestar atenção a algumas demonstrações que denunciam dor, como os movimentos corporais, expressões faciais, ou a solicitação frequente de calmantes. Ao centralizar suas ações para o bem estar do ser humano, avaliando a dor no idoso, têm condições de intervir de maneira adequada, implementando um cuidado que possa proporcionar o alívio da dor e o conforto ao indivíduo, possibilitando uma condição de vida mais humana, a fim de que o idoso possa enfrentar positivamente seu cotidiano e ter uma qualidade de vida satisfatória.

Frente a essas explanações, o objetivo deste estudo foi caracterizar a dor crônica em idosos residentes na cidade de Cruzaltense - RS, a fim de evidenciar a influência desta na vida diária e na convivência social.

MÉTODO

Estudo epidemiológico, observacional e descritivo, de corte transversal com coleta de dados prospectiva, com a finalidade de caracterizar a dor crônica em idosos residentes na comunidade de Cruzaltense - RS.

Fizeram parte do estudo 48 idosos residentes na área urbana do Município de Cruzaltense - RS, sendo que a população total de idosos residentes nesta área é de 54 . Este município conta, hoje, com uma população de 2.273 habitantes. ${ }^{6}$ Os critérios de inclusão centraram-se em ser residente da área urbana do município de Cruzaltense; ter idade igual ou superior a 60 anos e aceitar participar da pesquisa. Os seis idosos que não participaram deveu-se a não serem encontrados nas datas da visitação pela pesquisadora.

Inicialmente, a pesquisadora acadêmica identificou as residências em que havia idosos, indo de casa em casa para realizar o le- 
vantamento e, na oportunidade, investigou se o idoso apresentava dor e há quanto tempo. Os idosos que relataram ter dor há mais de seis meses foram caracterizados como tendo dor crônica e, assim, seguiram fazendo parte do estudo; os que não referiram dor foram excluídos da segunda etapa da pesquisa.

Os que continuaram responderam ao questionário contendo questões fechadas (Apêndice I), que foi investigado e anotado no formulário pela própria pesquisadora acadêmica.

O projeto foi aprovado pelo Comitê de Ética em Pesquisa da Universidade Regional Integrada do Alto Uruguai e das Missões - Campus de Erechim, estando registrado no SISNEP - CAAE pelo número: 0125.0.232.000-07. Os idosos que aceitaram participar da pesquisa assinaram o Termo de Consentimento Livre e Esclarecido, no qual deram seu consentimento para divulgação dos resultados, sendo garantido seu anonimato. A pesquisa foi conduzida dentro dos preceitos éticos da Resolução de Helsinki e das normas da Resolução no 196/ 96, da Comissão Nacional de Ética em Pesquisa (CONEP). ${ }^{?}$

\section{APRESENTAÇÃO E DISCUSSÃO DOS RESULTADOS}

Foram visitados todos os idosos que residem na área urbana do município de Cruzaltense - RS, totalizando 54 indivíduos, em seus domicílios, dos quais seis não se en- contravam em casa em nenhuma das três visitas. Assim, fizeram parte da etapa inicial do estudo 48 idosos que, quando perguntados se sentiam algum tipo de dor em seu dia a dia, 21 relataram não sentir nenhum tipo de dor, correspondendo a 43,75\% desta população. Destes 21 idosos, 13 têm idade entre 70 e 87 anos.

Diante desta constatação, seguiu-se para a segunda fase do estudo com 27 idosos, que correspondem a $56,25 \%$ dos que referiram apresentar dor há mais de seis meses. Destes, 16 idosos são do sexo feminino, representando 59,3\% e 11 do sexo masculino correspondendo a 40,7\%, com idade entre 60 anos e 83 anos, e média de 71,5 anos (tabela 1). Em estudo realizado numa população de 172 idosos, a presença da dor crônica foi observada em 107 indivíduos, correspondendo a $62,21 \%$ da amostra, sendo que no sexo feminino a prevalência foi de 69,3\%, e no masculino, de $52,1 \%{ }^{8}$

A dor crônica é hoje conceituada como um fenômeno complexo e multifatorial, que envolve aspectos orgânicos e psicossociais, e interfere sobremaneira na qualidade de vida da pessoa idosa. A dor confronta o idoso com sua fragilidade e ameaça sua segurança, por vezes, impedindo o convívio social, a realização das atividades de vida diária, consome sua renda e esgota de modo físico e psíquico tanto a pessoa como a família ou o cuidador.

Com referência ao estado civil atual, constatou-se que predominam os idosos casados $(55,6 \%)$, com um percentual signi- 
ficativo de viúvos $(40,7 \%)$ e somente $3,7 \%$ de divorciados (tabela 1). A dor física é mais fácil de controlar. O sentimento de solidão e o sofrimento, muitas vezes pela falta de companhia, é uma questão subjetiva e está vinculada aos valores da pessoa, levando a um sentimento de angústia, vulnerabilidade, perda de controle e ameaça à integridade do eu e, consequentemente, evidencia-se a queixa de dor. ${ }^{9}$

No que concerne à escolaridade, $63 \%$ não conseguiram completar o ensino fundamental e 37\% são analfabetos (tabela 1). Estes dados são significativos, pois refletem as condições sociais apresentadas no início do século passado, demonstrando que o acesso à educação era restrito. A possibilidade educacional há mais de meio século era muito baixa, e as pessoas precisavam trabalhar auxiliando no sustento da família, que na maioria das vezes era numerosa. $\mathrm{O}$ nível de escolaridade influencia sobremaneira no acesso à informação, o que pode ser determinante para uma melhora no quadro álgico. Também é decisiva no autocuidado, pois o idoso deve ser capaz de cuidar de si mesmo, e saber ler é fator contributivo.

Os resultados obtidos com relação à escolaridade estão de acordo com a maioria dos estudos conduzidos com idosos no Rio Grande do Sul. Estudo realizado na cidade de Estação - RS apontou que 88,2\% dos idosos entrevistados não completaram o ensino fundamental, apenas $3,9 \%$ possuíam o ensino fundamental completo e o ensino médio, somente $2 \%$ da população alvo con- seguiu atingir o ensino superior e ainda, $2 \%$ são analfabetos. ${ }^{9}$ Pesquisa semelhante realizada no Município de Veranópolis - RS, localidade em que o número de idosos chega a $12,63 \%$ da população, apresentou um índice de $51,9 \%$ de idosos com ensino fundamental incompleto, seguido de $21 \%$ com apenas o ensino fundamental completo, $\mathrm{e}$ $13,6 \%$ de analfabetos. ${ }^{10}$

Quanto à ocupação pregressa, 92,6\% eram agricultores, inclusive as 15 idosas do sexo feminino, e somente $7,4 \%$ correspondiam a dois idosos que tinham outra profissão - uma merendeira e um caminhoneiro (tabela 1). Em relação à ocupação atual, $3,7 \%$, o que representa uma pessoa, ainda trabalha na agricultura, $44,4 \%$ desenvolvem atividades no lar, $40,8 \%$ relataram não ter ocupação e 3,7\% são respectivamente, pedreiro, autônomo e caminhoneiro, sendo que algumas destas profissões requerem muito esforço físico (tabela 1). Este dado é condizente com a realidade da região do Alto Uruguai, local do campo da pesquisa, que se caracteriza por ser eminentemente agrícola. Este fato faz com que a população idosa tenha uma história de trabalho vinculada à agricultura. O esforço físico a que estiveram submetidos durante suas vidas pode ser um fenômeno que contribuiu para o surgimento da dor. Hoje, com a renda da aposentadoria agrícola, de um salário mínimo, não conseguem suprir suas necessidades básicas; soma-se a isto a falta de medicamentos oferecidos na rede pública, fazendo com que este idoso permaneça com dor e não consiga encontrar formas de alívio. 
Tabela 1 - O perfil sociodemográfico da amostra. Cruzaltense, RS. 2008.

\begin{tabular}{lc}
\hline Características & $\mathrm{n}=27 \%$ \\
\hline Idade (anos) - Média & 71,5 \\
Sexo & $11(40,7)$ \\
Masculino & $16(59,3)$ \\
Feminino & \\
Estado Civil & $15(55,6)$ \\
Casado & $11(40,7)$ \\
Viúvo & $1(3,7)$ \\
Divorciado & \\
Escolaridade & $10(37)$ \\
Não alfabetizado & $17(63)$ \\
Fundamental incompleto & \\
Reside com & $18(85,2)$ \\
Esposa, filhos e parentes & $3(11,1)$ \\
Sozinhos & $1(3,7)$ \\
Amigos & \\
Ocupação pregressa & $25(92,6)$ \\
Agricultor & $1(3,7)$ \\
Merendeira & $1(3,7)$ \\
Caminhoneiro & $12(44,5)$ \\
Ocupação atual & $10(40,7)$ \\
Do lar & $1(3,7)$ \\
Não tem ocupação & $1(3,7)$ \\
Agricultor & $1(3,7)$ \\
Pedreiro & \\
Autônomo & \\
Caminhoneiro & \\
\hline & \\
&
\end{tabular}

Com relação às condições de saúde referidas pelos idosos, $81,5 \%$ responderam apresentar diagnóstico médico para hipertensão em 70,4\%, seguida de depressão em 22,2\%, diabetes em $14,1 \%$, cardiopatias $11,1 \%$ (tabela 2), ainda foram mencionadas outras doenças como: artrose, osteoporose, disli- pidemias, labirintite e isquemia cerebral (7,4\%); osteófito, ciatálgia, hipotireoidismo, artrite, sinusite, hérnia inguinal (3,7\%). Alguns idosos referiram apresentar mais de um problema de saúde. No entanto, 18,5\% referiram não ter diagnóstico médico de patologias, mas sentem dor. 
Tabela 2 - Distribuição dos indivíduos de acordo com a situação de saúde. Cruzaltense, RS. 2008.

\begin{tabular}{lc}
\hline \multirow{2}{*}{ Variáveis } & Amostra total (n=27) \\
\cline { 2 - 2 } & $\mathrm{n}(\%)$ \\
\hline Tem problema de saúde & $22(81,5)$ \\
Sim & $5(18,5)$ \\
Não & \\
Problemas de saúde referidos & $19(70,4)$ \\
Hipertensão & $6(22,2)$ \\
Depressão & $4(14,1)$ \\
Diabetes & $3(11,1)$ \\
Cardiopatias & $2(7,4)$ \\
Artrose & $2(7,4)$ \\
Osteoporose & $2(7,4)$ \\
Laberintite & $2(7,4)$ \\
Isquemia cerebral & $2(7,4)$ \\
Dislipidemias & $1(3,7)$ \\
Osteofito & $1(3,7)$ \\
Ciatálgia & $1(3,7)$ \\
Hipotireoidismo (TSH) & $1(3,7)$ \\
Artrite & $1(3,7)$ \\
Esporão de calcâneo & $1(3,7)$ \\
Sinusite & $1(3,7)$ \\
Ácido úrico & $1(3,7)$ \\
Desgaste ósseo & $1(3,7)$ \\
Hérnia inguinal &
\end{tabular}

Segundo dados do Ministério da Saúde, ${ }^{11}$ mais de $85 \%$ dos idosos apresentam pelo menos uma enfermidade crônica, e $15 \%$ pelo menos cinco dessas doenças, entre as quais as mais frequentes são hipertensão e diabetes. A presença de patologias crônico-degenerativas, como o desgaste do sistema osteomuscular, inerente ao processo de envelhecimento, pode provocar dor.
Quanto à prevalência da dor crônica por local, os lugares mais prevalentes incidiram a coluna lombar $(44,4 \%)$, seguida pela região das pernas $(40,7 \%)$, articulação do joelho $(25,9 \%)$ e coluna cervical, membros superiores $(14,8 \%)$; com menos probabilidade de dor aparecem dedos dos pés e articulação do tornozelo $(7,4 \%)$, região cefálica, região do tórax, abdome e pés $(3,7 \%)$, segundo a tabela 3 . Alguns 
idosos referiram dor em mais de um local. Pesquisa realizada por Reis et al. ${ }^{12} \mathrm{em}$ 44 prontuários de pacientes portadores de lombalgia, com idade igual ou superior a 60 anos, verificou que $43,18 \%$ tinham dor do tipo crônica.

Tabela 3 - Distribuição dos indivíduos de acordo com o local da dor. Cruzaltense, RS. 2008.

\begin{tabular}{lc}
\hline Variável & $\begin{array}{c}\text { Amostra total } \\
\mathrm{n}(\%)\end{array}$ \\
\hline Local da dor & $12(44,4)$ \\
Coluna lombar & $11(40,7)$ \\
Região das pernas & $7(25,9)$ \\
Articulação do joelho & $4(14,8)$ \\
Coluna cervical & $4(14,8)$ \\
Membros superiores & $2(7,4)$ \\
Dedo dos pés & $2(7,4)$ \\
Articulação do tornozelo & $1(3,7)$ \\
Região cefálica & $1(3,7)$ \\
Região torácica & $1(3,7)$ \\
Região abdominal & $1(3,7)$ \\
Pés & \\
\hline
\end{tabular}

Em relação à intensidade da dor, utilizou-se a escala numérica verbal de intensidade da dor (VAS), que varia de 0 a 10 , sendo que 0 é considerado ausência de dor; de 1 a 3 - dor leve; 4 a 5 - dor moderada; de 6 a 7 - dor forte e de 8 a 10 - dor insuportável. ${ }^{13}$ Para o uso desta escala, se solicita ao indivíduo que avalie sua dor e transforme isto em uma nota de 0 a 10.

Os idosos referiram notas que variam de $1 \mathrm{a} 10$. Constatou-se que predominam as notas 5 e 8 , referidas por cinco idosos cada, correspondendo a $18,5 \%$, respectivamente; em seguida, as notas 4 e 6 , com quatro idosos, sinalizando $14,8 \%$ cada; as notas 2,7 e 10 com dois idosos, que correspondem a 7,4\% cada; e as notas 1,3 e 9 de somente um idoso, correspondendo a $3,7 \%$ cada. Interessante observar que 23 idosos $(85,18 \%)$ referiram dor considerada de moderada a alta.

A tentativa de analisar a duração, local e a frequência da recorrência da dor deveu-se à compreensão de que tais aspectos estariam ligados ao desconforto e comprometimento da qualidade de vida, influenciando a realização das atividades de vida diária, bem como o convívio social, já que inúmeros 
idosos, sobretudo com agravos crônicos à saúde, julgam que com a idade a dor é inevitável e tem de ser suportada. ${ }^{14}$ Em razão dessa concepção errônea, existem poucos estudos que abrangem a temática da dor na terceira idade.

Com relação ao tipo de dor, $40,7 \%$ dos idosos pesquisados referiram uma sensação de dolorimento; já para $37 \%$, a dor era tipo queimação; em 22,2\%, latejante; $11,1 \%$, lacerante; $7,4 \%$, aguda e $7,4 \%$, profunda, sendo que alguns idosos se queixaram de mais de um tipo de dor.

A frequência desta dor varia, sendo que a que prevalece em $48,1 \%$ dos pesquisados é a dor presente em todos os dias; em 29,7\%, apenas quando trabalham; já para $11,1 \%$, quase todos os dias; $3,7 \%$, duas vezes por mês; $3,7 \%$, quando caminham; e 3,7\%, de vez em quando. Dellaroza, Pimenta e Matsuo ${ }^{15}$ encontraram, em estudo com idosos, que a frequência da dor também varia, prevalecendo os episódios diários com $42,3 \%$ em membros inferiores, e em seguida nos outros locais: episódios semanais em 30,3\% e diários em $24,2 \%$ dos idosos pesquisados.

Constatou-se, também, que o horário do surgimento da dor ocorreu mais à noite, para $44,5 \%$ dos idosos; apresentar dor durante o dia foi referido por $18,5 \%$. O surgimento da dor está relacionado a alguma atividade, como levantar da cama ou da cadeira em 3,7\% dos casos; e ainda, 33,3\% relata- ram não ter horário frequente para sentir dor. Dos idosos pesquisados, somente 3,7\% (uma pessoa) não utilizam nenhum tratamento para aliviar a dor; os demais $96,3 \%$ sempre assumem um comportamento frente à dor, em muitas situações, realizando mais de um tipo de tratamento: $33,3 \%$ tomam medicamentos; $33,3 \%$ fazem massagem e 29,7\% passam Gelol, gel de arnica, pomada Cataflan, banha de peixe-boi ou álcool com tajujá.

Quanto ao uso de medicação oral para o alívio da dor, $77,8 \%$ fazem uso contínuo; $22,2 \%$ buscam outras alternativas. Dos $77,8 \%$ que usam medicamento para o alívio da dor, $22,2 \%$ ingerem mais de um tipo de medicação, sendo que um idoso faz uso de seis tipos de medicação de maneira intercalada. O uso indiscriminado de medicamentos para o alívio da dor é um risco iminente à saúde. Interações medicamentosas podem ocorrer quando os efeitos e/ou a toxicidade de um fármaco são alterados pela presença de outro. São geralmente imprevistas e indesejáveis.

Os medicamentos mais ingeridos são: diclofenaco de sódio $(28,6 \%)$, piroxicam $(23,8 \%)$, dipirona (19\%), paracetamol e ibuprofeno $(14,3 \%)$, atroveram e reumazim forte $(9,5 \%)$ - este medicamento é proveniente do Paraguai - e Celebra 200mg, Doril, Superhisti, Buscopam Injetável, Calmador e Reumasil (3,7\%); e um idoso (3,7\%) não soube dizer que medicamento usa e não o tinha em casa no momento da visita (tabela 4). 
Tabela 4 - Distribuição dos idosos com dor crônica quanto às medidas terapêuticas farmacológicas utilizadas para o controle da dor. Cruzaltense, RS, 2008.

\begin{tabular}{llc}
\hline Classificação farmacológica & \multicolumn{1}{c}{ Principio ativo } & $\mathrm{N} \%$ \\
\hline Antiinflamatórios não-esteróides & Diclofenaco de sódio & $6(28,6)$ \\
& & \\
& Piroxicam & $5(23.8)$ \\
& Ibuprofeno & $3(14,3)$ \\
& Celebra 200mg & $1(3,7)$ \\
Analgésico e Antitérmico & Dipirona & $4(19)$ \\
& Paracetamol & $3(14,3)$ \\
Analgésico e Antiespasmódico & Atroveram & $2(9,5)$ \\
Anticolinérgico & Buscopam injetável & $1(3,7)$ \\
Analgésico e Antipirético & Doril & $1(3,7)$ \\
& Calmador & $1(3,7)$ \\
Anti-histamínico e Analgésico & Superhisti & $1(3,7)$ \\
Antiinflamatório & Reumasil & $1(3,7)$ \\
& Reumazim forte & $1(3,7)$ \\
\hline
\end{tabular}

Averiguou-se que, em 59,1\% dos idosos em uso de medicação, esta ocorre por indicação médica; $13,7 \%$, por indicação de parentes; $9,1 \%$, de vizinhos e o mesmo percentual por conta própria; outros $4,5 \%$, do dentista e 4,5\%, de amigos. O que chama a atenção é o índice elevado de automedicação - 40,9\%. Pesquisa realizada na cidade de Bambuí, com 1.383 idosos, revela que $69,1 \%$ dos idosos que usam medicação consomem exclusivamente medicamentos prescritos; $6,4 \%$, medicamentos não prescritos e $10,7 \%$ consomem simultaneamente medicamentos prescritos e não prescritos. ${ }^{16}$

Quando questionados até que ponto a presença da dor afeta a realização das ativi- dades de vida diária, 33,3\% responderam mais ou menos; $25,9 \%$, bastante; $22,2 \%$, muito pouco; $3,7 \%$, completamente e para $14,9 \%$ não afeta em nada. Portanto, a dor afeta, de alguma maneira, $85,1 \%$ da população-alvo.

As atividades de vida diária restritas pela dor mais caracterizadas são: 44,4\% - transferência/locomoção; 37\% - vestuário; 14,8\% - trabalhar e banho; higiene pessoal - 7,4\% e em apenas $22,2 \%$ dos idosos a dor não afeta em nada. Portanto, a dor sentida pela maioria dos idosos afeta de alguma maneira as atividades da vida diária, sendo que alguns idosos têm mais do que uma atividade restrita. 
Um fato importante relatado por $48,2 \%$ dos entrevistados é que a dor não limita sua capacidade em participar de atividades sociais. No entanto, para 33,3\%, a dor afeta bastante; em $11,1 \%$, muito pouco; 7,4\%, mais ou menos. É interessante observar que em $51,8 \%$ dos idosos a presença da dor compromete, de alguma maneira, a realização das atividades sociais, como ir à igreja $(22,2 \%)$, dançar $(18,5 \%)$, passear e participar do grupo da terceira idade $(14,8 \%)$, viajar $(11,1 \%)$, caminhar e trabalhar $(7,4 \%)$; e para $3,7 \%$, participar do baile da terceira idade, fazer ginástica, crochê, dar ensinamento da catequese, sendo que alguns idosos têm mais de uma atividade da vida social restrita.

Alguns idosos relataram que mesmo com dor não deixam de manter um convívio social, denotando a relevância desta prática na vida do ser humano. Redes de suporte social contribuem para que o indivíduo acredite que é cuidado, amado e valorizado, se sentindo pertencente ao grupo, em que possam dar e receber apoio emocional. Portanto, os relacionamentos sociais são significativos no processo de envelhecer.

Vale ressaltar que nem todos os indivíduos percebem a dor da mesma forma, podendo ser considerada produto de experiências passadas de dor, de valores, de expectativas culturais e emocionais, estando vinculadas tanto ao aspecto fisiológico quanto psicológico.

\section{CONSIDERAÇÕES FINAIS}

Este estudo permitiu caracterizar a dor em um grupo de idosos, sendo possível acreditar que a presença desta, em 56,25\% dos entrevistados, possa estar associada à atividade laboral pregressa, questões de gênero e doenças crônicas. A realização do trabalho agrícola em $96,2 \%$ dos indivíduos exigia bastante esforço físico, principalmente se levados em consideração os aspectos reais daquela época. Outro dado relevante é o fato de a dor ser prevalente em mulheres, podendo estar vinculado à dupla ou tripla jornada de trabalho: agricultura, lar e filhos.

A dor está entre os principais fatores limitadores da possibilidade do idoso manter seu cotidiano de maneira normal, impactando negativamente a qualidade de vida do indivíduo idoso, prejudicando de algum modo à realização das atividades de vida diária, bem como restringindo, em algumas situações, a convivência, levando-os ao isolamento social.

Detectou-se também que muitos idosos sentem dor e convivem com ela diariamente, tentando manter a aparência de uma vida normal. Alguns motivos os levam a não se queixarem, talvez pelo temor em serem mal interpretados, tachados de poliqueixosos, ou ainda, já terem se acostumado com a nãovalorização de sua dor.

A dor é uma sensação subjetiva, podendo ser física e/ ou psíquica, devendo ser sempre considerada, diante da angústia e vulne- 
rabilidade que imprime sobre o indivíduo, ameaçando sua integridade. Diante deste entendimento, os profissionais de saúde, ao valorizarem a dor referida pelos idosos, têm a possibilidade de orientar e intervir de modo a minimizar este sofrimento, para que este idoso possa ter uma qualidade de vida satisfatória. Além de conhecer, avaliar e tratar a dor no idoso, o desafio maior está em intervir de modo comprometido, alicerçado na ética e na eficácia.

Mesmo com as obscuridades que rondam a complexidade de se avaliar a dor no idoso, cabe à enfermagem assumir papel preponderante relacionado a esta questão. Deve desenvolver sensibilidade, habilidade e conhecimento, apontando novas estratégias de cuidado e tornando públicos os saberes em prol de um melhor viver na velhice e um envelhecimento livre de dor. Ao olhar para a dor no idoso, é essencial que se perceba sua subjetividade, ser sensível, ter consciência e consideração com o ser humano que a sente. Para tanto, é imprescindível que estas discussões sejam realizadas na formação acadêmica, porque muitos profissionais não possuem conhecimento sobre o controle da dor crônica. Este despreparo leva à não-avaliação da dor de forma sistemática, sua banalização e a ignorar o impacto devastador da dor para o idoso.

A enfermagem se preocupa com o cuidado à pessoa numa variedade de situações relacionadas à saúde. Desta forma, o cuidar inclui assumir papéis significativos na atenção ao idoso com dor, no sentido de diagnosticar, intervir e monitorar os resultados do tratamento. Estabelecer vínculos de confiança e atitudes de interesse pelo ser humano que tem dor, cuidando-o de maneira holística.

\section{REFERÊNCIAS}

1. Merskey H, Bogduk NB, editors. Classification of chronic pain: descriptions of chronic pain syndromes and definitions of pain terms. 2. ed. Seattle: IASP Press; 1994.

2. Pedroso RA, Celich KLS. Dor: quinto sinal vital, um desafio para cuidar em enfermagem. Revista Texto \& Contexto Enfermagem 2006; 15(2): 270-6.

3. Silva MCS. Dor no idoso. In: Terra NL, Dornelles B, organizadores. Envelhecimento bem-sucedido. Porto Alegre: EDIPUCRS, 2002, p.161-5.

4. Andrade FA, Pereira LV, Sousa FAE. Mensuração da dor no idoso: uma

revisão. Rev Lat Am Enfermagem 2006 mar-abr; 14(2): 271-6.

5. Sousa JM. Um olhar sobre a dor do idoso. In: Leão ER, Chaves LD. Dor: $5^{\circ}$ sinal vital: reflexões e intervenções de enfermagem. Curitiba: Matinari; 2004. p.263-74.

6. Instituto Brasileiro de Geografia e Estatística. Censo Demográfico: Brasil, 2007. [Acesso em: 2007 out. 11].

Disponível em: < http:// www.ibge.gov.br $>$.

7. Resolução 196/96. Conselho Nacional Saúde. 1996 out 10. Estabelece normas sobre pesquisas envolvendo seres humanos. Pub DOU 201, [out 10,1996]. 
8. Dellaroza MSG, et al. Caracterização da dor crônica e métodos analgésicos utilizados por idosos da comunidade. Rev Assoc Med Bras 2008; 54(1): 36-41.

9. Silva RB. Perfil socioeconômico e de saúde dos idosos participantes do grupo de convivência "conviver" no município de Estação / RS. [monografia]. Erechim: Universidade Regional Integrada do Alto Uruguai e das Missões; 2007.

10. Farenzena WP. Qualidade de vida em um grupo de idosos de Veranópolis-RS. [dissertação]. Porto Alegre: Pontifícia Universidade Católica do Rio Grande do Sul; 2007.

11. Brasil. Ministério da saúde. Ações buscam garantir a qualidade de vida do idoso. 2004. [Acesso em: 2008 maio 09]. Disponível em: < http:// portalweb02.saude.gov.br/saude/ visualizar_texto.efm? idtx $=18050>$.

12. Reis LA, et al. Lombalgia na terceira idade: distribuição e prevalência na
Clínica Escola de Fisioterapia da Universidade Estadual do Sudoeste da Bahia. Revista Brasileira de Geriatria e Gerontologia 2008; 11(1): 93-103.

13. Sakata RK, et al. Avaliação da dor. In: Cavalcanti IL, Maddalena ML, editores. Dor. Rio de Janeiro: Sociedade de Anestesiologia do Estado do Rio de Janeiro; 2003. p.53-94.

14. Roach SS. Introdução à enfermagem gerontológica. Rio de Janeiro: Guanabara Koogan, 2003.

15. Dellaroza MSG, Pimenta CAM, Matsuo T. Prevalência e caracterização da dor crônica em idosos não institucionalizados. Cad Saúde Pública 2007; 23(5): 1151-60.

16. Loyola Filho AI, et al. Estudo de base populacional sobre o consumo de medicamentos entre idosos: Projeto Bambuí. Cad Saúde Pública 2005; 21(2): 545-53. 


\section{Apêndice 1 \\ Instrumento para a coleta de dados}

\begin{tabular}{|c|c|c|}
\hline 1) Sexo: & ( ) feminino & ( ) masculino \\
\hline \multicolumn{3}{|l|}{ 2) Data de nascimento: } \\
\hline \multicolumn{3}{|l|}{ 3) Idade: } \\
\hline \multirow[t]{2}{*}{ 4) Estado Civil: } & ( ) solteiro & ( ) viúvo/a \\
\hline & ( ) casado/a & ( ) divorciado/separado \\
\hline \multirow[t]{4}{*}{ 5) Escolaridade: } & ( ) analfabeto & ( ) alfabetizado sem frequentar escola \\
\hline & ( ) fundamental incompleto & ( ) fundamental completo \\
\hline & ( ) ensino médio incompleto & ( ) ensino médio completo \\
\hline & ( ) superior incompleto & ( ) superior completo \\
\hline \multirow[t]{3}{*}{ 6) Com quem reside? } & ( ) sozinho & ( ) amigos \\
\hline & ( ) esposo/a & ( ) outros \\
\hline & ( ) filhos & \\
\hline \multicolumn{3}{|l|}{ 7) Ocupação pregressa: } \\
\hline \multicolumn{3}{|l|}{ 8) Ocupação atual: } \\
\hline 9) Tem problemas de saúde? & $\operatorname{Sim}()$ & Não ( ) \\
\hline \multirow{4}{*}{$\begin{array}{l}\text { 10) Somente para os que } \\
\text { responderem sim a questão } \\
\text { anterior. Qual? }\end{array}$} & ( ) hipertensão & ( ) alcoolismo \\
\hline & ( ) diabetes & ( ) depressão \\
\hline & ( ) osteoporose & ( ) outras. Quais: \\
\hline & ( ) dislipidemias & \\
\hline \multirow{8}{*}{$\begin{array}{l}\text { 11) Somente para os que } \\
\text { responderem sim a questão } \\
\text { anterior. Local da dor: }\end{array}$} & ( ) cabeça & ( ) abdome \\
\hline & ( ) garganta, ouvido & ( ) coluna - região \\
\hline & ( ) ombro, braço, antebraço & $\longrightarrow$ \\
\hline & ( ) mão & ( ) pernas \\
\hline & ( ) dedos da mão & ( ) articulação do joelho \\
\hline & ( ) articulação do cotovelo & ( ) articulação do tornozelo \\
\hline & ( ) articulação do punho & ( ) pés \\
\hline & ( ) tórax, peito & ( ) dedos dos pés \\
\hline \multirow[t]{5}{*}{ 12) Tipo de dor: } & ( ) aguda & ( ) bem localizada \\
\hline & ( ) em pontada & ( ) aperto \\
\hline & ( ) lacerante & ( ) dolorimento \\
\hline & ( ) queimação & ( ) latejante \\
\hline & ( ) profunda & \\
\hline \multicolumn{3}{|l|}{$\begin{array}{l}\text { 13) Nota referida conforme } \\
\text { VAS (escala da dor): }\end{array}$} \\
\hline \multirow{3}{*}{$\begin{array}{l}\text { 14) De quanto em quanto } \\
\text { tempo você sente dor? }\end{array}$} & ( ) todos os dias & ( ) uma vez por semana \\
\hline & ( ) dia sim, dia não & ( ) duas vezes por mês \\
\hline & ( ) duas vezes por semana & ( ) Outra. Quantos? \\
\hline
\end{tabular}


Apêndice 1

Instrumento para a coleta de dados (continuação)

\begin{tabular}{|c|c|c|}
\hline $\begin{array}{l}\text { 15) Existe um horário mais } \\
\text { frequente para o seu } \\
\text { surgimento? }\end{array}$ & $\begin{array}{l}\text { ( ) não } \\
\text { ( ) sim }\end{array}$ & Qual? \\
\hline \multicolumn{3}{|l|}{$\begin{array}{l}\text { 16) O que faz para aliviar a } \\
\text { dor? }\end{array}$} \\
\hline $\begin{array}{l}\text { 17)Toma algum remédio } \\
\text { para dor? }\end{array}$ & $\begin{array}{l}\text { ( ) não } \\
\text { ( ) sim }\end{array}$ & Quais? \\
\hline $\begin{array}{l}\text { 18) Somente para os que } \\
\text { responderem sim a questão } \\
\text { anterior. Quem indicou? }\end{array}$ & $\begin{array}{l}\text { ( ) médico } \\
\text { ( ) vizinho } \\
\text { ( ) parente }\end{array}$ & $\begin{array}{l}\text { ( ) amigo } \\
\text { ( ) Outro. Quem? }\end{array}$ \\
\hline $\begin{array}{l}\text { 19) Até que ponto a presença } \\
\text { da dor afeta sua vida diária? }\end{array}$ & $\begin{array}{l}\text { ( ) nada } \\
\text { ( ) muito pouco } \\
\text { ( ) mais ou menos }\end{array}$ & $\begin{array}{l}\text { ( ) bastante } \\
\text { ( ) completamente }\end{array}$ \\
\hline $\begin{array}{l}\text { 20) Aos que responderem } \\
\text { afirmativamente as questões } \\
20 \text { citar quais atividades da } \\
\text { vida diária são restringidas: }\end{array}$ & $\begin{array}{l}\text { ( ) banho } \\
\text { ( ) vestuário } \\
\text { ( ) higiene pessoal } \\
\text { ( ) transferência e/ou locomoção }\end{array}$ & $\begin{array}{l}\text { ( ) continência } \\
\text { ( ) alimentação }\end{array}$ \\
\hline $\begin{array}{l}\text { 21) Você sente que a } \\
\text { presença da dor limita sua } \\
\text { capacidade de participar em } \\
\text { atividades? }\end{array}$ & $\begin{array}{l}\text { ( ) nada } \\
\text { ( ) muito pouco } \\
\text { ( ) mais ou menos }\end{array}$ & $\begin{array}{l}\text { ( ) bastante } \\
\text { ( ) completamente }\end{array}$ \\
\hline $\begin{array}{l}\text { 22) Aos que responderem } \\
\text { afirmativamente as questōes } \\
21 \text { citar quais atividades } \\
\text { sociais são restringidas. }\end{array}$ & & \\
\hline
\end{tabular}

